\title{
The Ambient Particular Matter Pollution Situation and its Health Effect in China
}

\author{
Baoqing Wang, Deqing Wang, Shuai Yin, and Shu Yao
}

\begin{abstract}
Particular matter is the main pollutant for the ambient environment in China. Some $\mathbf{P M}_{10}$ pollution index data were analyzed for four different cities. Exposure-response between $\mathbf{P M}_{10}, \mathbf{P M}_{2.5}$ and daily mortality of inhabitants in China was discussed. Epidemiological literature of $\mathbf{P M}_{10}, \mathbf{P M}_{2.5}$ and daily mortality were extracted using Endnote, and the relationship between $\mathbf{P M}_{10}, \mathbf{P M}_{2.5}$ and daily mortality of inhabitants using meta-analysis method. The results show that the air pollution index average value is $92.8,74,67.9$ and 75.1 for Beijing, Shanghai, Guangzhou and Chongqing, respectively. It is more serious for $\mathbf{P M}_{10}$ pollution in Beijing than other three cities. The daily mortality of inhabitants increase by $0.29 \%$ (95\% CI: $0.21 \%-0.38 \%)$ and $0.56 \%$ (95\% CI: $0.40 \%-0.72 \%)$, as the concentration of $\mathbf{P} \mathbf{M}_{10}, \mathbf{P M}_{2.5}$ increase a certain degree $\left(10 \mu \mathrm{g} / \mathrm{m}^{3}\right)$. The results of meta-analysis can provide the scientific basis for particular matter pollution control. The related control measurements should be made to reduce PM pollution.
\end{abstract}

Index Terms- $\mathrm{PM}_{10}, \mathbf{P M}_{2.5}$, Meta-analysis, pollution situation, control measurement.

\section{INTRODUCTION}

Inhalable particle matter is less than $10 \mu \mathrm{m}$ in aerodynamic diameter, also called $\mathrm{PM}_{10}$. Fine particle matter is less than $2.5 \mu \mathrm{m}$ in aerodynamic diameter, also called $\mathrm{PM}_{2.5}$. Particulate matter (PM) is the main air pollutants in China at present [1]. It is very serious for the atmospheric environment situation in China. It has not been controlled completely for the traditional coal pollution, but it has become increasingly prominent for regional complex atmospheric pollution of $\mathrm{PM}_{2.5}$, acid rain and $\mathrm{O}_{3}$. $\mathrm{PM}$ pollution emissions include the primary particle matter, and the secondary particle matte such as $\mathrm{SO}_{2}, \mathrm{NO}_{\mathrm{x}}, \mathrm{VOCs}, \mathrm{NH}_{3}$ precursor. In February 2012, the Ambient Air Quality Standard was revised. Among the health effects endpoints death arouses the maximal loss [2], [3]. Meta-analysis method is used to analyze the data collected from the relevant epidemiological literature and found the exposure-response relationship between exposure to the air particulate matter and increased percentage of daily mortality. It is not enough for PM and its health effect in China, so related research should be made in the future.

Manuscript received November 28, 2012; revised December 5, 2012. This work was financially supported by National Major Scientific Instrument Equipment Development Special (2011YQ060111) and Environmental Protection Commonweal Industry Scientific Research Project (201009032).

The authors are with College of Environmental Science and Engineering, Nankai University, Tianjin, China (e-mail: wbqchina@163.com).

\section{PM POLLUTION SITUATION}

With the rapid development of economy and society, the present pollution situation is very serious, for example, coal consumption rose sharply, vehicle quantities increased dramatically, $\mathrm{NO}_{\mathrm{x}}$ and VOCs emissions grown significantly, $\mathrm{O}_{3}$ and $\mathrm{PM}_{2.5}$ pollution aggravated. It has not been solved completely for $\mathrm{PM}_{10}$ and total suspended particles (TSP) pollution, at the same time it was serious for $\mathrm{PM}_{2.5}$ and $\mathrm{O}_{3}$ pollution in the region of Beijing-Tianjin-Hebei, Yangtze river delta, pearl river delta, and so on.

In September 2011, the WHO declared a global air pollution city report shows that China's air quality ranking is the 77th in 91 countries. Although it has no comprehensive monitoring data for $\mathrm{PM}_{2.5}$, the related monitoring has been carried out.

The 30 data were selected and analyzed for $\mathrm{PM}_{10}$ from October to November 2012. Air pollution index for Beijing, Shanghai, Guangzhou and Chongqing of China are shown in Fig. 1. The four cities were selected because of their serious PM pollution and different region location. From this it can be reflected to the whole China.

As the Shown from Fig. 1, the air pollution index average value is 92.8, 74, 67.9 and 75.1 for Beijing, Shanghai, Guangzhou and Chongqing, respectively. $\mathrm{PM}_{10}$ is prior and main pollutant. For Beijing, $\mathrm{PM}_{10}$ pollution is more serious than other three cities.

For Beijing, the sources of $\mathrm{PM}_{10}$ were soil/crustal, coal combustion, motor vehicle, oil combustion, the secondary particulate and biomass combustion, which contributed $21.3 \%, 18.2 \%, 16.5 \%, 14.7 \%, 6.6 \%$ and 22.8 , respectively [4].

For Shanghai, the sources of $\mathrm{PM}_{2.5}$ (no PM10 data) were soil/crustal, coal combustion, motor vehicle, oil combustion, steel and other, which contributed 11\%, 9\%, 22\%, 2\%, 18\% and 37, respectively [5].

For Guangzhou, it showed that urban dust, coal combustion, oil combustion, the secondary particulate, biomass combustion, industrial emission and other were the sources of $\mathrm{PM}_{10}$, which contributed 20.7\%, 14.3\% , $17.8 \%, 10.4 \%, 6.3 \%, 16.3 \%$ and $14.2 \%$, respectively [6].

For Chongqing, the sources of $\mathrm{PM}_{10}$ were coal combustion, motor vehicle, road dust, cement, steel and other, which took $18.35 \%, 15.11 \%, 20.48 \%, 27.22 \%, 3.74 \%$ and $15.10 \%$, respectively [7]. 


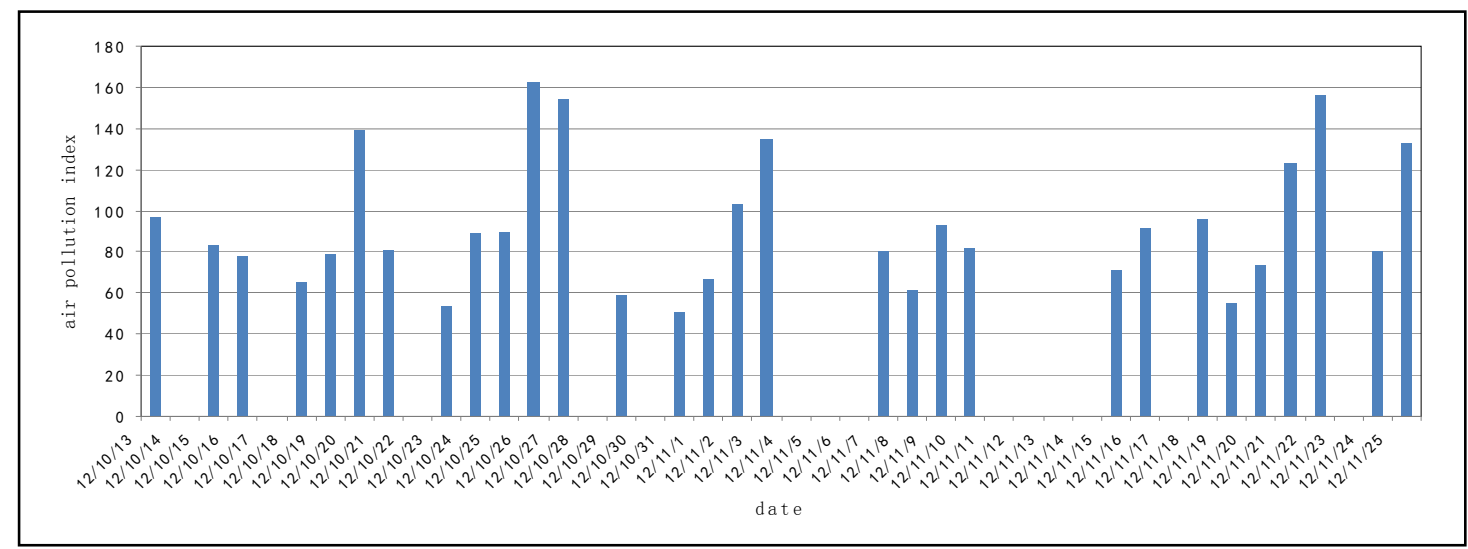

(a)

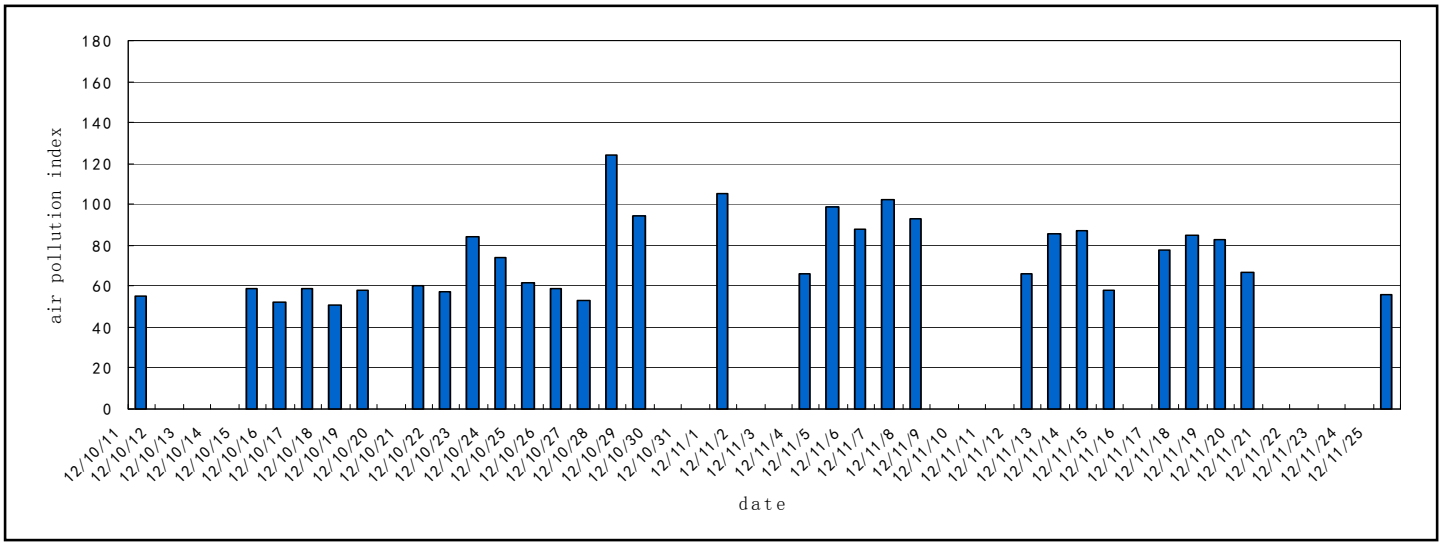

(b)

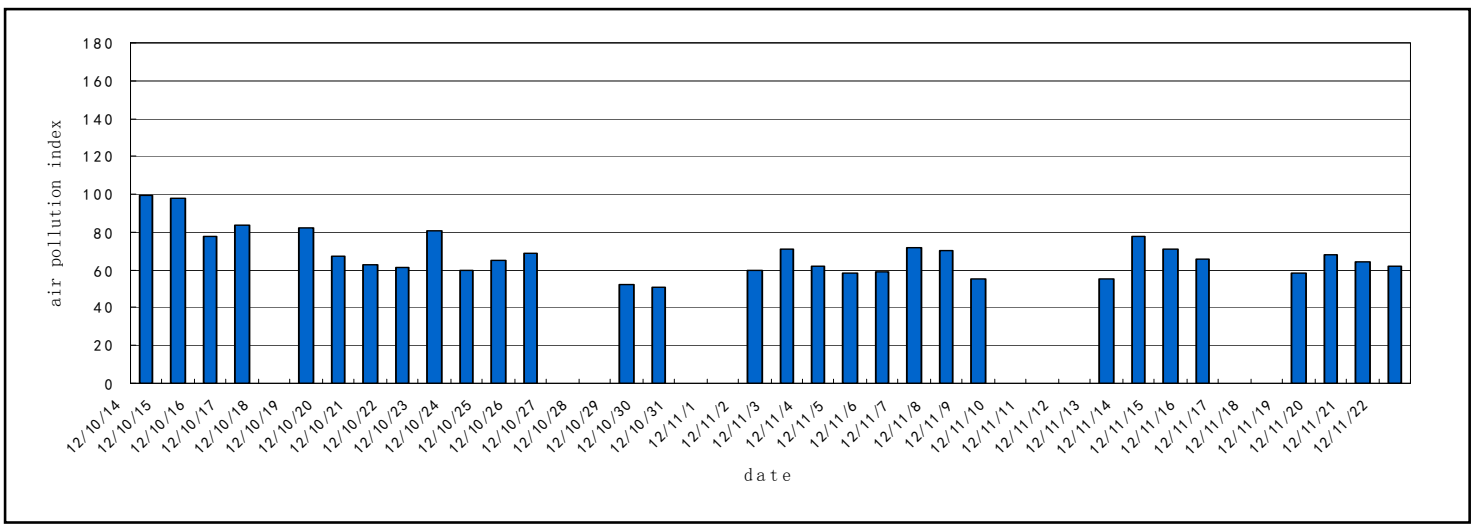

(c)

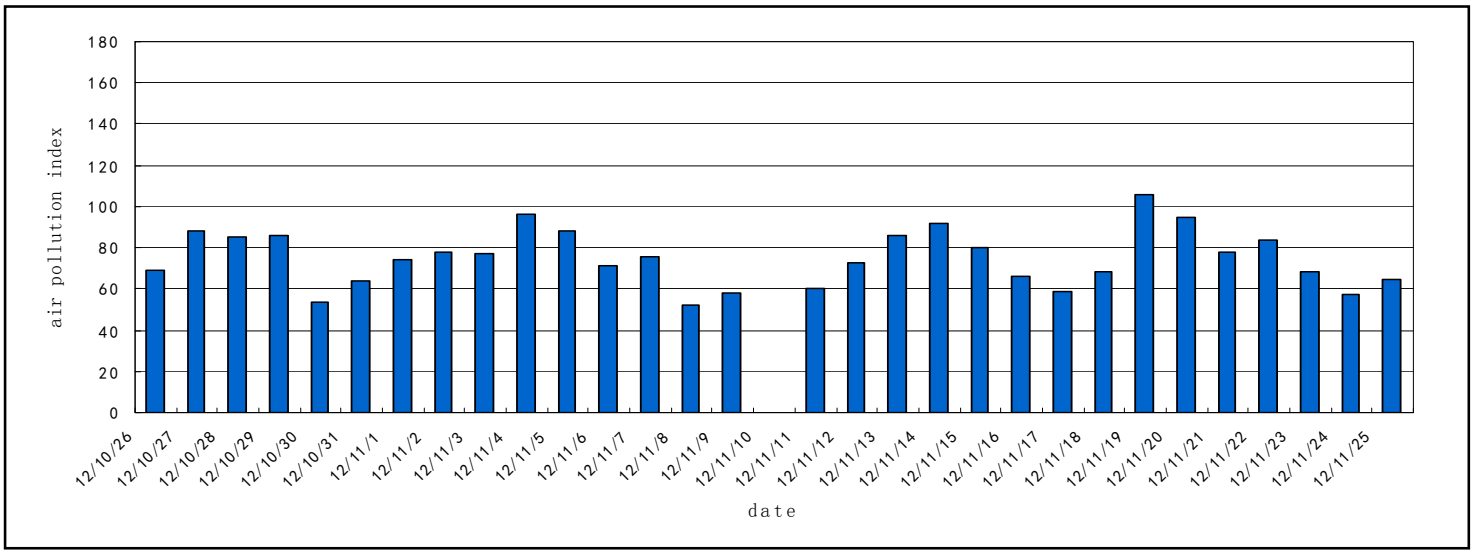

(d)

Fig. 1. Air pollution index for different city in China from October to November 2012, (a) Beijing (b) Shanghai (c) Guangzhou (d) Chongqing. 


\section{HEAlth EFFECT ANALysE}

\section{A. Meta-Analysis}

The general step of Meta-analysis involves collection of literature, extract of data and evaluation and explanation of the result. It has been used for the percentage and standard error of the daily mortality change of the inhabitants associated with the concentration increase of PM, transformed the standard deviation using formula (represents the total sample) and analyzed by Revman5.1 software. The final results of Meta-analysis are expressed by increase of daily mortality of inhabitants associated with the concentration of $\mathrm{PM}_{10}, \mathrm{PM}_{2.5}$ (increased by $10 \mu \mathrm{g} / \mathrm{m}^{3}$ ).

Epidemiological literature about the relationship between PM pollution and daily mortality in inhabitants published during 1990 to 2012. For literature, it is necessary to collect the data from the literature left, read the literature and select high persuasion of data, and enter the data and save into the database of the PM exposure-effects relationship of human health.

\section{B. Results}

Through statistical tests and analysis, we calculated and adjusted to get the final data with high degree of accuracy. All the data were List in Table I and Table II . The forest plot and funnel plot of the influence between the increase of $\mathrm{PM}_{10}$ concentration and inhabitants mortality are showed in Fig. 2 and Fig. 3.

TABLE I: MORTALITY CHANGE FOR A $10 \mu \mathrm{G} / \mathrm{M}^{3}$ INCREASE OF PM $\mathrm{PM}_{10}$ CONCENTRATION IN CHINA

\begin{tabular}{llll}
\hline \hline Author & Year & Area & Mortality (\%) \\
\hline Chen [8] & $2004-2008$ & Beijing, Shanghai & 0.25 \\
Kan [9] & $2004-2005$ & Shanghai & 0.16 \\
Qian [10] & $2000-2004$ & Wuhan & 0.36 \\
Wong [11] & $1995-1997$ & Hong Kong & 0.6 \\
Wong a[12] & $2001-2004$ & Shanghai & 0.26 \\
Wong b[12] & $2001-2004$ & Hong Kong & 0.53 \\
Dai [13] & $2001-2004$ & Shanghai & 0.54 \\
\hline \hline
\end{tabular}

TABLE II: MORTALITY CHANGE FOR A $10 \mu \mathrm{G} / \mathrm{M}^{3}$ INCREASE OF PM $\mathrm{PM}_{2.5}$ CONCENTRATION IN CHINA

\begin{tabular}{llll}
\hline \hline Author & Year & Area & Mortality (\%) \\
\hline Dai [14] & $2002-2003$ & Shanghai & 0.36 \\
Kan [15] & $2004-2005$ & Shanghai & 0.85 \\
Ma [16] & $2006-2008$ & Shenyang & 0.50 \\
Yang [17] & $2007-2008$ & Guangzhou & 0.9 \\
Zhao [18] & 2004-2008 & Xi’an & 0.41 \\
\hline \hline
\end{tabular}

Fig. 2 shows that the concentration of $\mathrm{PM}_{10}$ increased a certain degree $\left(10 \mu \mathrm{g} / \mathrm{m}^{3}\right)$, the daily mortality of inhabitants increased by $0.29 \% \quad$ (95\%CI:0.21\%-0.38\%). In the chi-square test, $\mathrm{I}^{2}=45 \%$, indicates heterogeneity between different literatures is moderate, $\mathrm{Z}=7.09$ ( $\mathrm{P}<0.00001$ ), illustrates the analysis has some statistical significance, the inspection effect is ideal.

Fig. 3 shows that the data points are well-distributed on the both sides of the center line, reveals the symmetrical funnel shape which means that the publication bias in this analysis is positive.

\begin{tabular}{|c|c|c|c|c|c|c|}
\hline \multirow{2}{*}{$\begin{array}{l}\text { Studv or Subgroup } \\
\text { Chen } 2011\end{array}$} & \multirow{2}{*}{$\begin{array}{r}\text { Mortality } \\
0.25\end{array}$} & \multicolumn{2}{|c|}{ SE Weight } & \multirow[t]{2}{*}{$\begin{array}{c}\text { Mortality } \\
\text { N, Fixed, 95\% Cl }\end{array}$} & \multicolumn{2}{|c|}{$\begin{array}{c}\text { Mortality } \\
\text { N, Fixed, 95听 Cl }\end{array}$} \\
\hline & & 0.09 & $21.2 \%$ & & & $\rightarrow$ \\
\hline Dai 2004 & 0.16 & 0.07 & $35.1 \%$ & $0.16[0.02,0.30]$ & & - \\
\hline Kan 2007 & 0.36 & 0.09 & $21.2 \%$ & $0.36[0.18,0.54]$ & & $\rightarrow$ \\
\hline Qian 2007 & 0.6 & 0.28 & $2.2 \%$ & $0.60[0.05,1.15]$ & & \\
\hline Wong 2008 & 0.53 & 0.14 & $8.8 \%$ & $0.53[0.26,0.80]$ & & \\
\hline Wong 2008 a & 0.26 & 0.19 & $4.8 \%$ & $0.26[-0.11,0.63]$ & & \\
\hline Wong 2008 b & 0.54 & 0.16 & $6.7 \%$ & $0.54[0.23,0.85]$ & & \\
\hline Total $(95 \% \mathrm{Cl})$ & & & $100.0 \%$ & $0.29[0.21,0.38]$ & & $\bullet$ \\
\hline $\begin{array}{l}\text { Heterogeneity } \mathrm{Ch}^{2}= \\
\text { Test for overall effect }\end{array}$ & $\begin{array}{l}10.87, d f=6 \\
Z=7.09(P\end{array}$ & $\begin{array}{l}6(P=0 \\
<0.000\end{array}$ & $\begin{array}{l}0.09)_{1}^{2}= \\
001)\end{array}$ & $=45 \%$ & $\begin{array}{cc}-1 & -0.5 \\
\text { yours experimental }\end{array}$ & 0.5 \\
\hline
\end{tabular}

Fig. 2. The forest plot of influence of $\mathrm{PM}_{10}$ increased by average $10 \mu \mathrm{g} / \mathrm{m}^{3}$ on daily mortality of inhabitants

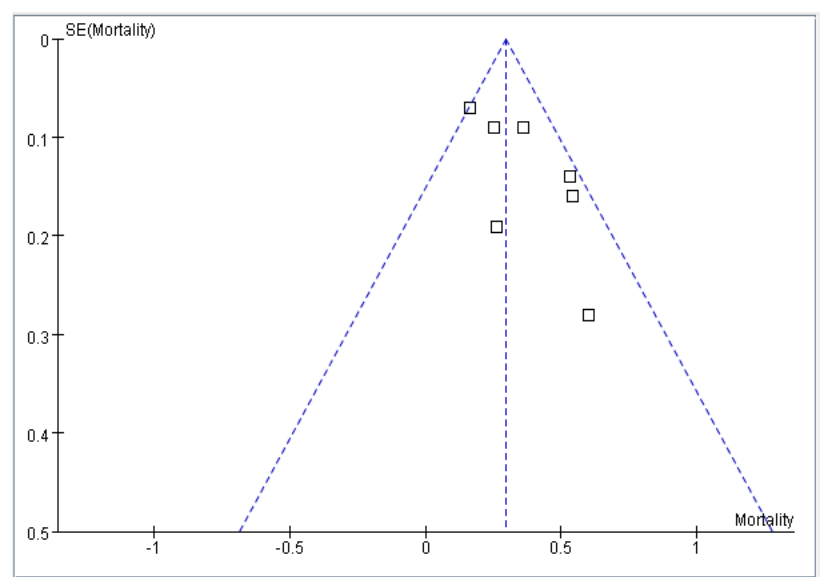

Fig. 3. The funnel plot of influence of $\mathrm{PM}_{10}$ increased by average $10 \mu \mathrm{g} / \mathrm{m}^{3}$ on daily mortality of inhabitants

The forest plot and funnel plot of the influence between the increase of $\mathrm{PM}_{2.5}$ concentration and inhabitants mortality are showed in Fig. 4 and Fig. 5.

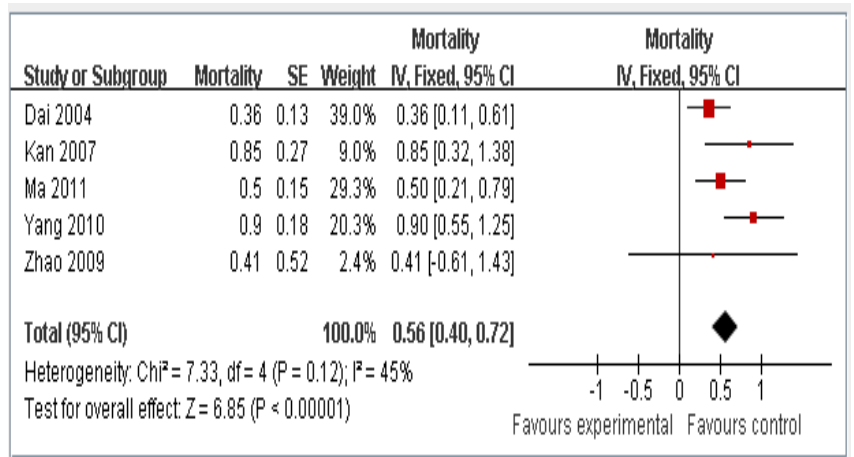

Fig. 4. The forest plot of influence of $\mathrm{PM}_{2.5}$ increased by average $10 \mu \mathrm{g} / \mathrm{m}^{3}$ on daily mortality of inhabitants

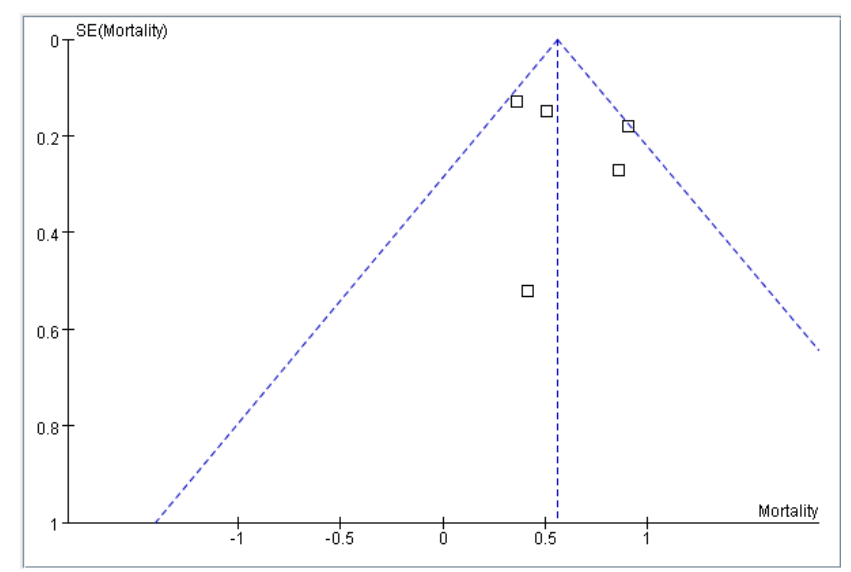

Fig. 5. The funnel plot of influence of PM2.5 increased by average $10 \mu \mathrm{g} / \mathrm{m}^{3}$ on daily mortality of inhabitants 
Fig. 4 shows that the concentration of $\mathrm{PM}_{2.5}$ increased a certain degree $\left(10 \mu \mathrm{g} / \mathrm{m}^{3}\right)$, the daily mortality of inhabitants increased by $0.56 \%$ (95\%CI:0.40\%-0.72\%). In the chi-square test, $\mathrm{I}^{2}=45 \%$, indicates heterogeneity between different literatures is moderate, $\mathrm{Z}=7.33$ ( $\mathrm{P}<0.00001$ ), illustrates the analysis has some statistical significance, the inspection effect is ideal.

Fig. 5 shows that the data points aren't well-distributed on the both sides of the center line which means that the publication bias in this analysis is negative.

\section{CONCLUSION}

The PM pollution is serious in China, although its pollution level is different. So we should pay attention to PM pollution and its health effect.

The relationship between increased percentage of daily mortality and the concentration of $\mathrm{PM}_{10}, \mathrm{PM}_{2.5}$ were obtained. $\mathrm{PM}_{10}, \mathrm{PM}_{2.5}$ increased a certain degree $\left(10 \mu \mathrm{g} / \mathrm{m}^{3}\right)$, the daily mortality of inhabitants in China increased by $0.29 \%$ (95\% CI: $\quad 0.21 \%-0.38 \%), \quad 0.56 \% \quad(95 \% \quad$ CI: $\quad 0.40 \%-0.72 \%)$, respectively. Publication bias is the most common system error in Meta-analysis. Possible reasons include the followed, such as omitting some data during the Endnote retrieval and document quotation and the subjective influence of researchers.

The Ambient Air Quality Standard (GB3095-2012) was enacted on February 2012. In consideration of the complexity source and component of $\mathrm{PM}_{2.5}$, and the increase of the motor vehicle, the difficulties in $\mathrm{PM}_{2.5}$ pollution and monitoring increase gradually. As a result, we should develop the particulate matter monitoring and controlling, enhance the research about the health effect and epidemiology studies for the further environmental decision-making.

In order to control PM pollution, the control measurements are followed, such as determining environmental capacity according to the different region character, implementing zone integrated and making the improvement target, emphasizing scientific planning and ensuring the multiple investment, optimizing the economic structure and implementing cooperative pollution control, strengthening monitoring supervision, promoting the policy implementation, and so on.

\section{ACKNOWLEDGMENT}

This work was financially supported by National Major Scientific Instrument Equipment Development Special (2011YQ060111) and Environmental Protection Commonweal Industry Scientific Research Project (201009032).

\section{REFERENCES}

[1] 2011 China environment bulletin, Ministry of Environmental Protection of the People's Republic of China. 2011.

[2] H. Dai and W. Song, "Health influence of atmosphere $\mathrm{PM}_{2.5}$," Foreign Medicalsciences (Section Hygiene), vol. 28, pp. 299-303, 2001.
[3] G. Lin, X. Zhao, and Y. Du, “Association between short-term exposure to air inhalable particulate matter and daily mortality in residents- A Meta-analysis," Chinese Journal of Health Inspection, vol. 16, pp. 324-329, 2009.

[4] T. Chen, L. Hua, and L. Jin, "Sources apportionment of $\mathrm{PM}_{10}$ in Beijing,” China Environmental Monitoring, vol. 6, pp. 59-63, 2006.

[5] W. Yue, X. Li, and J. Liu, "Research $\mathrm{PM}_{2.5}$ pollution source based on the single particle analysis," The Third Session of National Environmental Chemistry Academic Conference, pp. 12-13, 2005.

[6] M. Cui, X, Wang, and H. Su, Chemical Characters and Sources Identification of PM10 in Guangzhou Area," Acta Scientiarum Naturalium Universitatis Pekinensis, vol. 44, pp. 459-466, 2008.

[7] Q. Zhao, Q. Zhao, D, Zhang, and T. Ye, "Research on PM10 Source Apportionment in Main Districts of Chongqing," Environment and Ecology in the Three Gorges, vol. 3, pp. 14-17, 2008.

[8] R. Chen, Y. Li, and Y. Ma, "Coarse particles and mortality in three Chinese cities: the China Air Pollution and Health Effects Study (CAPES),” Science Total Environment, vol. 409, pp. 4934-4938, 2011.

[9] H. Kan, S. London, and G. Chen, "Differentiating the effects of fine and coarse particles on daily mortality in Shanghai China," Environment International, vol. 33, pp. 376-384, 2007.

[10] Z. Qian, Q. He, and H. Lin, "Association of daily cause-specific mortality with ambient particle air pollution in Wuhan, China,” Environmental Research, vol. 105, pp. 380-389, 2007.

[11] C. Wong, S. Ma, and A. Hedley, "Effect of air pollution on daily mortality in Hong Kong,” Environmental Health Perspectives, vol. 109, pp. 335-340, 2001.

[12] C. Wong, N. VichitVadakan, and H. Kan, "Public health and air pollution in Asia (PAPA): a multicity study of short-term effects of air pollution on mortality,” Environmental Health Perspectives, vol. 116, pp. 1195-1202, 2008.

[13] H. Dai, W. Song, and X. Gao, "Study on relationship between ambient $\mathrm{PM}_{10}, \mathrm{PM}_{2.5}$ pollution and daily mortality in a district in Shanghai," Journalof Hygiene Research, vol. 33, pp. 293-297, 2004.

[14] H. Dai, “Air fine particulate matter pollution character and health effect research in Shanghai,” Shanghai: Occupational and Environmental Health, Fudan University, pp. 40-43, 2003.

[15] H. Kan, W. Song, and X. Qian, "Meta-analysis of association between air fine particulate matter and daily mortality," Journal of Environmental and Health, vol. 22, pp. 246-248, 2005

[16] Y. Ma, R. Chen, G. Pan, X. Xu, W. Song, B. Chen, and H. Kan, "Fine particulate air pollution and daily mortality in Shenyang China," Sci Total Environ, vol. 409, pp. 2473-2477, 2011

[17] C. Yang, X. Peng, W. Huang, R. Chen, X. Xu, B. Chen, and H. Kan., "A time-stratified case-crossover study of fine particulate matter air pollution and mortality in Guangzhou, China,” Int Arch Occup Environ Health, vol. 10, pp. 1007-1011, 2011.

[18] K. Zhao, J. Cao, and M. Wen, "Correlation between $\mathrm{PM}_{2.5}$ pollution in Air and mortality of residents in urban area, Xi'an," Journal of Preventive Medicine Information, vol. 27, pp. 257- 262, 2011.

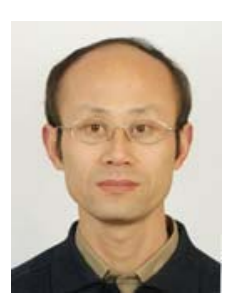

Baoqing Wang was born in Tangshan, Hebei Province, China in 1972. He received her first degree in Environmental Engineering from Kunming University of Science and Technology in 1996, Master Degree in 2001 from Kunming University of Science and Technology, and Doctor Degree in 2004 from Xi'an University of Architecture and Technology. His research interests include air pollution control theory and simulation, atmospheric particulates environmental quality criterion, air particles exposure and health effect and environmental pollution control planning and management.

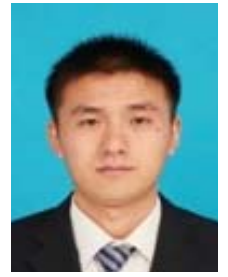

Deqing Wang was born in Linyi, Shandong Province, China in 1987. In the period from 2005 to 2009, he was educated in Environmental Planning and Management, Shandong University of Science and Technology. From 2010 to now, he is a postgraduate of Environmental Science and Technology, Nankai University. He has been studying in the field of PM pollution and its health effect. 